\section{The Educational Travails of a Visually-Impaired 25 Year-Old Nigerian University Student with Stargardt's Disease}

Abdulraheem O. Mahmoud ${ }^{1 *}$, Lateefat B. Olokoba1, Victoria A. Olatunji ${ }^{1}$ and Olubayo O. Kolawole ${ }^{2}$

\begin{abstract}
Stargardt's disease is probably under-diagnosed in sub-Saharan Africa as its subtle macular changes in the earlier stages of the disease are often out of proportion to the bilateral gradual impairment of central vision. In addition, the paucity of well-equipped eye clinics manned by trained retinal sub-specialists makes the detection of the disease a rare event. We present a patient in whom we made a diagnosis of Stargardt's disease on clinical grounds in Nigeria and who subsequently had corroboratory fundus angiographic and electro diagnostic tests in the United Kingdom. The patient, who was already severely visually incapacitated in his mid-twenties, had to abandon medical studies for a perceived less visually demanding one. His hope for a restoration of his eyesight now rests on the promising advances being made in gene and stem cell therapy.
\end{abstract}

\section{Keywords}

Stargardt's disease; Fundus flavimaculatus; Retinal stem cell therapy

\section{Introduction}

Stargardt's disease, also known as juvenile macular degeneration or fundus flavimaculatus, is an inherited juvenile macular degeneration that causes progressive vision loss usually to the point of legal blindness. Karl Stargardt, a German ophthalmologist [1], first described it in 1909. It is typically a bilateral and symmetrical condition, that is characterised by a progressive loss of central vision but the peripheral visual fields can be moderately to extensively restricted in the advanced stage of the disease [2]. The visual loss is because of degeneration of retinal photoreceptors at the macular causing atrophy at a later stage. Stargardt disease is an autosomal recessive inheritable condition. The gene for Stagardt's disease is located on the short arm of chromosome 1 and a mutation in the $A B C A 4$ gene is believed to be responsible [3]. The disease affects over 25,000 Americans and its prevalence is estimated to be 1:8,000 $1: 10,000$ [4]. Presentation is usually in the first to second decades of life with bilateral gradual impairment of central vision, which may be out of proportion to the macular changes, so that the child may

*Corresponding author: Abdulraheem O. Mahmoud, Department of Ophthalmology, Ilorin Teaching Hospital, P.O. Box 13834, Ilorin 240008, Nigeria, E-mail:mahmoud_ao@yahoo.com

Received: January 27, 2013 Accepted: February 12, 2013 Published: February 19, 2013 be suspected of malingering. Paucity of well-equipped eye clinics manned by trained retinal sub-specialists in a developing world setting such as Nigeria makes the detection of the disease a very rare event. In this light that we describe a patient in whom we made a diagnosis of Stargardt disease on clinical grounds in Nigeria and who subsequently had corroboratory fundus angiographic and electro diagnostic tests abroad.

\section{Case Report}

The 25-year-old male university undergraduate presented to our clinic in 2008 because of painless progressively worsening poor vision in both eyes of 2 years duration. Vision loss was initially observed for distance visual acuity and later on also for near visual acuity. The patient described objects as appearing wavy and distorted while focusing on them from distance and some parts of letters appeared missing while reading. A spectacle correction for short sightedness $(-2.00)$ had been prescribed for him 10 years earlier but vision had continued to diminish in spite of the glasses. His past ocular and medical histories were unremarkable. No known member of his family has had an eye disease or become blind. He is not on any chronic medication or local herbal concoction. His genotype is AA and he is neither a diabetic nor a hypertensive.

When he presented to us in 2008 , he was in the final year of his preclinical studies in medical school. He had to abandon his medical training because of his worsening visual condition and switched to a non-clinical course which he deemed to be less visually demanding. At present (2013), he has studied with great difficulty to the final year class of his new course.

His examination findings were as follows: unaided visual acuities of $1 / 60 \mathrm{OD}$ and $2 / 60 \mathrm{OS}$, which improved with pinhole to $6 / 36$, OD and 6/36 OS. With his spectacles, his visual acuities were 6/36 OD and $6 / 36$ OS. Near vision was N18 at $30 \mathrm{~cm}$. The anterior segment, lens and vitreous were normal bilaterally. The optic discs were pink with cup to disc ratios of 0.3 . The maculae were dry with good fovea reflex bilaterally. The perimacular discrete yellowish-white flecks bilaterally correspond to the circular patch of auto-fluorescence in the red free pre-angiographic fundus picture (first two shots in the upper row of figure 1). Intra ocular pressures were $11 \mathrm{mmg}$ in both eyes.

A clinical diagnosis of Stargardt disease was made and he was counselled on the absence of a definitive treatment and poor prognosis for significant visual recovery. He requested us to give him a referral letter to the United Kingdom for a second opinion and to benefit from sophisticated diagnostic and treatment modalities that might be available there. The same diagnosis of Stargardt disease was confirmed in the U.K. following his ocular examination and ocular investigations as outlined below. There was a much reduced macular electroretinogram (ERG) but paramacular area and retinal periphery were still functioning which was consistent with Stargardt disease. Fundus fluorescein angiography (FFA) also confirmed the Stargardt's picture (Figure 1) with the generalized dark choroid effect, prominent retinal circulation, and window defects corresponding to the flecks. Optical coherence tomography (OCT) showed normal retinal thickness (Figure 2). Colour vision was normal but contrast sensitivity was reduced OD 5/25 at $100 \mathrm{~cm}$ and OS 4/25 at $100 \mathrm{~cm}$. 
Citation: Mahmoud AO, Olokoba LB, Olatunji VA, Kolawole OO (2013) The Educational Travails of a Visually-Impaired 25 Year-Old Nigerian University Student with Stargardt's Disease. Int J Ophthalmic Pathol 2:2.

doi:http://dx.doi.org/10.4172/2324-8599.1000110

Overview Report

SPECTRALIS $\otimes$ Tracking Laser Tomography

Patient:

Patient ID: - -

Diagnosis: -..

OD, AF 30. ART [HS]

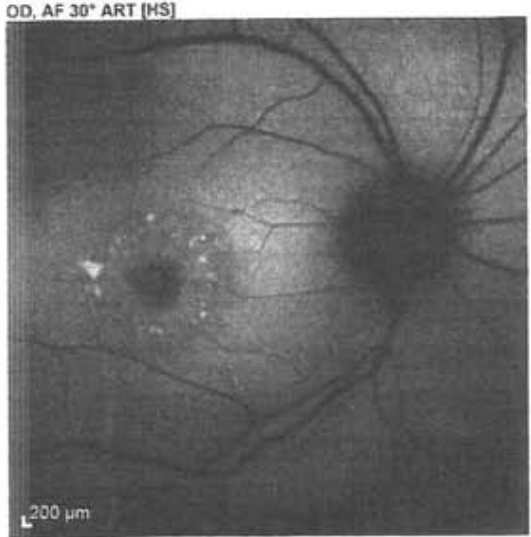

OS, AF $30^{\circ}$ ART IHS
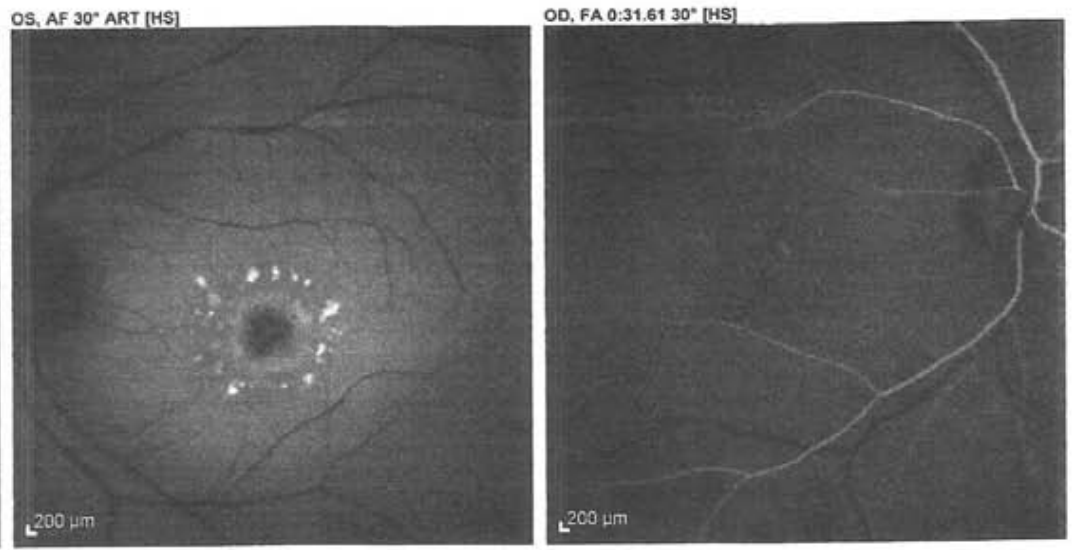

\section{DHEIDELBETL EกGIחEERIIG}

Sex:

M

Exam.: 12/Jun/2012

Comment: --
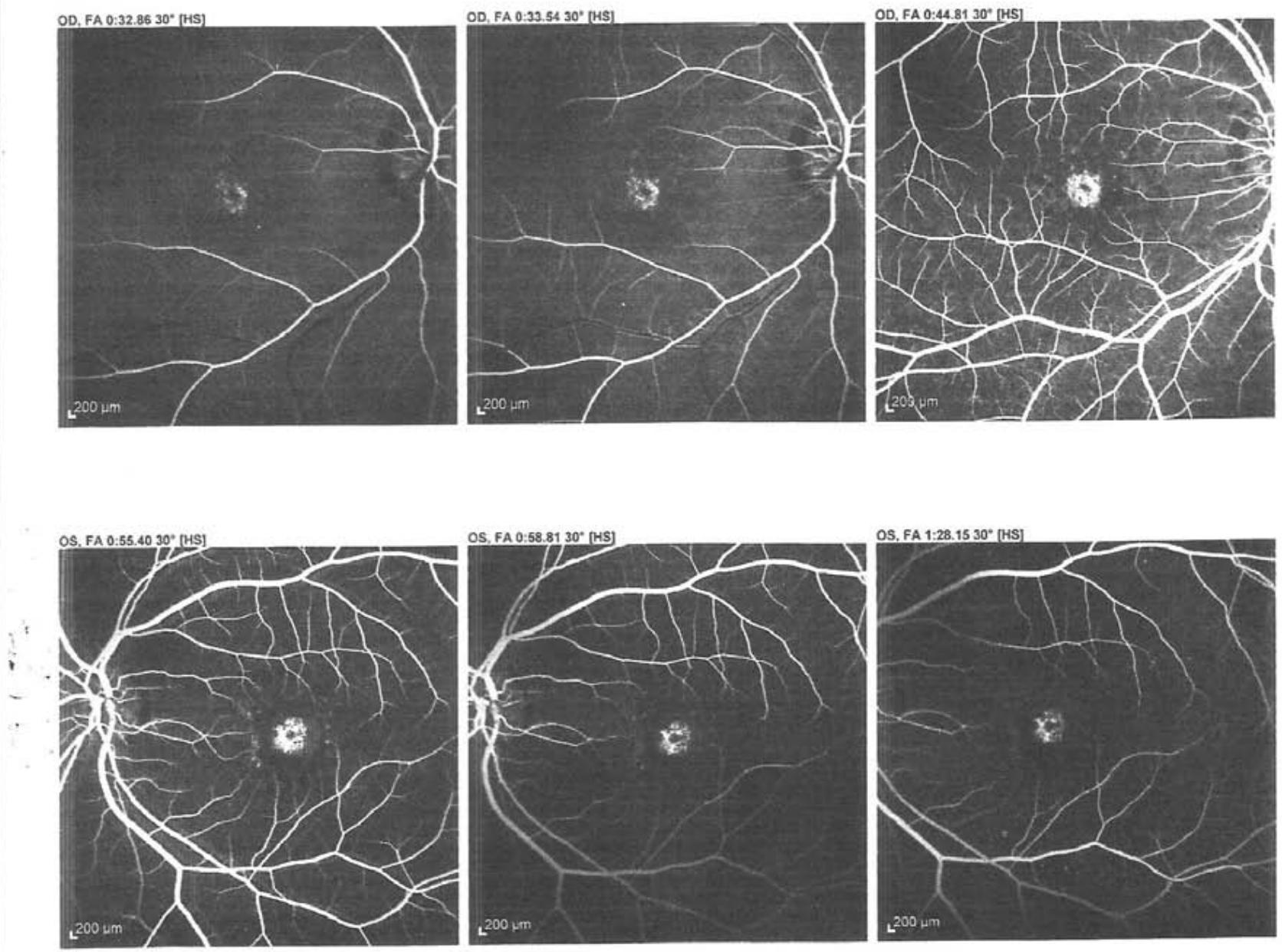

Figure 1: Fundus fluorescein angiographic picture of a 25 year old with Stargardt's disease. 
Citation: Mahmoud AO, Olokoba LB, Olatunji VA, Kolawole OO (2013) The Educational Travails of a Visually-Impaired 25 Year-Old Nigerian University Student with Stargardt's Disease. Int J Ophthalmic Pathol 2:2.

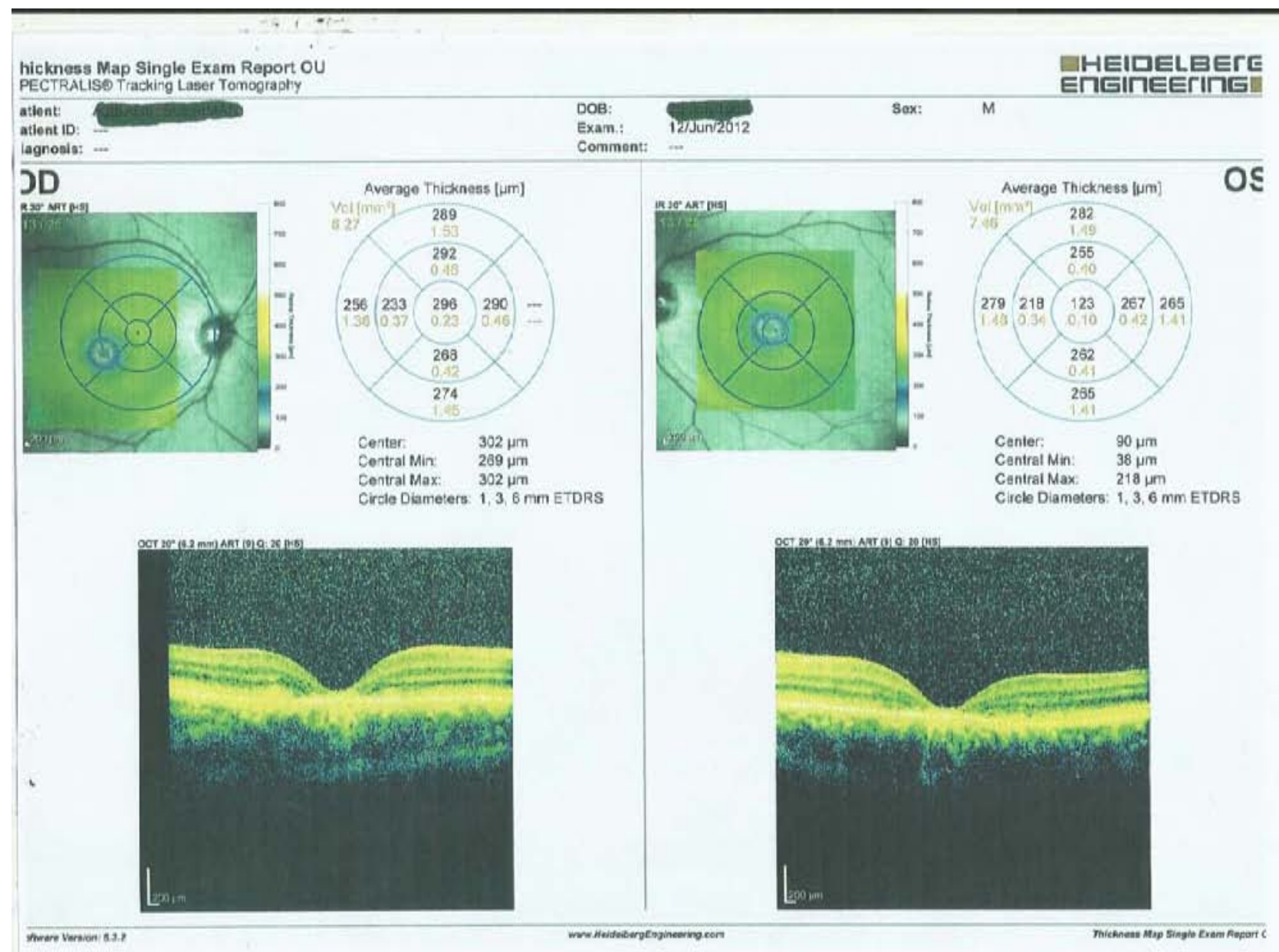

Figure 2: Optical Coherence Tomography of a 25 year old with Stargardt's disease.

A low vision assessment in our clinic revealed an improvement in distant vision to 0.1 (log mar) with $6 \mathrm{x}$ telescope. He is currently on the telescope as low vision device and -2.50DS-1.00 CYL axis $180 \mathrm{OD}$ and $-2.50 \mathrm{DS}-150 \mathrm{CYL}$ axis $180 \mathrm{OS}$.

\section{Discussion}

The combination of vision loss during teenage years and the perimacular flecks are characteristic for Stargardt's disease and differentiate this case from dominant drusen, fundus albunctatus, early North Carolina macular dystrophy, and benign fleck retina. The finding of a normal retinal thickness on OCT (Figure 2) corroborated our finding of a normal gross appearance of the macular. Apart from providing further corroboratory evidence, the ERG was also helpful in suggesting a favourable prognosis with the electroretinogram picture of a functioning perimacular area.

Both Stagardt's disease and fundus flavimaculatus described by Franceschetti [5] in 1965 describe the same condition as the latter most probably represents a more advanced and widespread stage of the former. Excessive storage of lipofuscin within the retinal pigment epithelium blocks the view of the choroid during FFA, hence the "dark or silent" choroid sign seen in our patient in figure 1 [6]. FFA is the most helpful of diagnostic tests in confirming diagnosis and excluding differentials as it proved out to be in our patient. A recent advance in this direction involves the use of the combination of fundus auto fluorescence with high resolution OCT in diagnosing the disease [7]. This non-invasive technique allows for an earlier detection of typical morphological changes not seen in clinical fundoscopy is feasible [7].

In an effort at classifying the myriad of fundoscopic findings in Stagardt disease, Noble and Carr [8] describes four basic patterns while Aaberg [9] described the degree and severity of the disease. A more recent review of the natural history of the various stages of severity that may be seen during the progression of Stargardt's macular dystrophy by Walia and Fishman [10], which was based upon fundus and electrophysiological findings can be summed up as follows:

Stage 1: characterized by the presence of variable pigmentary changes in the macula typified by a ring of flecks often circumscribes an area within 1 disc diameter on all sides of the fovea. Initially, relative and eventually absolute central or paracentral scotomas are seen. Normal results are most frequently obtained on electroretinogram (ERG) and electro-oculogram (EOG) testing.

Stage 2: characterized by the presence of fundus flecks beyond 1 disc diameter of the margin from the fovea. Peripheral visual fields are normal, a relative central scotoma may be observed in patients 
with macular involvement. ERG amplitudes and EOG ratios are most often normal.

Stage 3: characterized by the presence of diffusely resorbed flecks and choriocapillaris atrophy within the macula.EOG testing shows subnormal ratios for light peak to dark trough, subnormal cone or cone and rod ERG amplitudes are often recorded. Central field defects are similar to those in stage 2 , however, a degree of peripheral or mid-peripheral field impairment may be evident.

Stage 4: characterized by the presence of diffusely resorbed flecks, extensive choriocapillaris as well as retinal pigment epithelial cell atrophy throughout the fundus. Peripheral fields are moderately to extensively restricted. ERG testing shows notably reduced cone and rod amplitudes.

The general conclusion from the review above was that patients with Stargardt's disease who had fundus flecks and atrophic-appearing retinal changes that are limited to the macula have an overall better visual prognosis than patients with more extensive disease. Our patient, whose lesions are confined to the perimacular region, could therefore hopefully expect to continue to enjoy his vision, albeit in the present reduced scale, well into the future.

The absence of a positive family history of the disease from our patient may either reflect the fact that other members of the family who may have variants of the disease without a significant visual impairment or reluctance by Africans to volunteer a history of blinding conditions because of the stigma attached to it. ERG result provided evidence for normal functioning of paramacular area and retinal periphery, but the vision loss is disabling enough to force to change his course of study.

This degenerative disease may be treated in the future by gene therapy, but unfortunately most of this work is still at the preclinical phase [11]. Advances in stem cell therapy appears to be greater as approval for the first-ever human trial using retina cells derived from human embryonic stem cells to treat patients with Stagardt's macular dystrophy had been given as far back in 2010 .

\section{References}

1. Stargardt K (1909) Uber familiar, progressive degeneration in der Makulagegend des Auge. Graefe Arch Clin Exp Ophthalmol 71: 534-550.

2. Fishman GA (1976) Fundus flavimaculatus. A clinical classification. Arch Ophthalmol 94: 2061-2067.

3. Kaplan J, Gerber S, Larget-Piet D, Rozet J, Dollfus H, Dufier J, et al. (1993) A gene for Stargardt's disease (fundus flavimaculatus) maps to the short arm of chromosome. Nat Genet 5: 308-311.

4. Blacharski $P(1988)$ Retinal dystrophies and degenerations. In: Newsome DA, Raven Press, New York.

5. Franceschesti A (1963) Uber tapeto-retinale degeneration im klinder augenheikunde. Ferdinand Enke Verlag, Stuttgart 107-120

6. Fish G, Grey R, Sehmi KS, Bird AC (1981) The dark choroid in posterior retinal dystrophies. Br J Ophthalmol 65: 359-363.

7. Kortüm K, Kernt M, Reznicek L (2012) Significance of Ophthalmological imaging in common hereditary retinal diseases. Klin Monbi Augenhelilkd.

8. Noble KG, Carr RE (1979) Stargardt's disease and fundus flavimaculatus. Arch Ophthalmol 97: 1281-1285

9. Aaberg TM (1986) Stargardt's disease and fundus flavimaculatus: evaluation of morphologic progression and intrafamilial co-existence. Trans Am Ophthalmol Soc 84: 453-487.

10. Kinnunen K, Yla-Herttulala S (2012) Gene therapy in age related macula degeneration and hereditary macular disorders. Front Biosci (Elite Ed) 4 2546-2557.

11. Ong JM, da Cruz L (2012) A review and update of the current status of stem cell therapy and the retina. Br Med Bull 102: 133-146.

\section{Author Affiliations}

${ }^{1}$ Department of Ophthalmology, University of Ilorin Teaching Hospital, Ilorin, Nigeria

${ }^{2}$ Department of Ophthalmology, Ladoke Akintola University of Technology

Teaching Hospital, Oshogbo, Nigeria

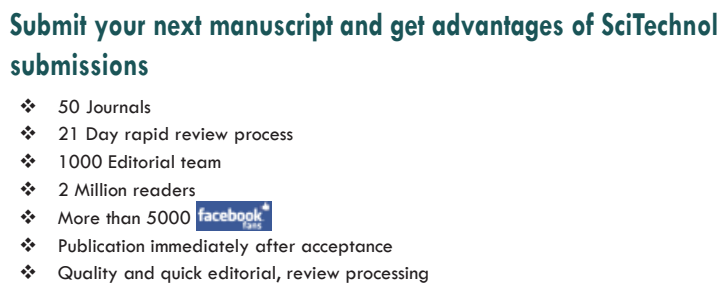

Submit your next manuscript at • www.scitechnol.com/submission 